\title{
Assessment of potential effects of the electromagnetic fields of mobile phones on hearing
}

\author{
Ingrida Uloziene*1, Virgilijus Uloza², Egle Gradauskiene ${ }^{2}$ and \\ Viktoras Saferis ${ }^{1}$
}

\author{
Address: ${ }^{1}$ Institute for Biomedical Research of Kaunas University of Medicine, Eiveniu 4, Kaunas, Lithuania and ${ }^{2}$ Department of Otolaryngology, \\ Kaunas University of Medicine, Eiveniu 2, Kaunas, Lithuania \\ Email: Ingrida Uloziene* - uloziene@kmu.lt; Virgilijus Uloza - uloza@kmu.lt; Egle Gradauskiene - gradauskiene@one.lt; \\ Viktoras Saferis - viktoras@kmu.lt \\ * Corresponding author
}

Published: 19 April 2005

BMC Public Health 2005, 5:39 doi:10.1 186/1471-2458-5-39

This article is available from: http://www.biomedcentral.com/I47/-2458/5/39

(c) 2005 Uloziene et al; licensee BioMed Central Ltd.

This is an Open Access article distributed under the terms of the Creative Commons Attribution License (http://creativecommons.org/licenses/by/2.0), which permits unrestricted use, distribution, and reproduction in any medium, provided the original work is properly cited.
Received: 18 December 2004

Accepted: 19 April 2005

\begin{abstract}
Background: Mobile phones have become indispensable as communication tools; however, to date there is only a limited knowledge about interaction between electromagnetic fields (EMF) emitted by mobile phones and auditory function. The aim of the study was to assess potential changes in hearing function as a consequence of exposure to low-intensity EMF's produced by mobile phones at frequencies of 900 and $1800 \mathrm{MHz}$.
\end{abstract}

Methods: The within-subject study was performed on thirty volunteers (age 18-30 years) with normal hearing to assess possible acute effect of EMF. Participants attended two sessions: genuine and sham exposure of EMF. Hearing threshold levels (HTL) on pure tone audiometry (PTA) and transient evoked otoacoustic emissions (TEOAE's) were recorded before and immediately after 10 min of genuine and/or sham exposure of mobile phone EMF. The administration of genuine or sham exposure was double blind and counterbalanced in order.

Results: Statistical analysis revealed no significant differences in the mean HTLs of PTA and mean shifts of TEOAE's before and after genuine and/or sham mobile phone EMF 10 min exposure. The data collected showed that average TEOAE levels (averaged across a frequency range) changed less than $2.5 \mathrm{~dB}$ between pre- and post-, genuine and sham exposure. The greatest individual change was $10 \mathrm{~dB}$, with a decrease in level from pre- to post- real exposure.

Conclusion: It could be concluded that a 10-min close exposure of EMFs emitted from a mobile phone had no immediate after-effect on measurements of HTL of PTA and TEOAEs in young human subjects and no measurable hearing deterioration was detected in our study.

\section{Background}

Due to wide spread use of the Global System for Mobile Communications (GSM) mobile phones they have become indispensable as communication tools and therefore any consequent biological effects should be consid- ered as a high-priority environmental health issue. However, to date, there is an inadequate knowledge on what biological systems could be affected by the use of these devices. Biological effects of radio-frequency electromagnetic fields (EMF) transmitted by mobile phones are 
still a matter of public and scientific discussion. Sensations of burning or warmth around the ear [1], headache [2], disturbance of sleep [3], alteration of cognitive functions and neural activity $[4,5]$, as well as alteration of the blood-brain barrier and a relative decrease in regional cerebral blood flow have been reported as effects resulting from mobile phone use [6,7]. The potential tumorous effect of EMFs is still a subject of debates and research [8$11]$.

The hearing system is in the closest proximity to the device so that hearing is potentially the most affected target of thermal and non-thermal effects. Moreover, the hearing system and particularly the cochlear outer hair cells (OHC) are known to be highly sensitive to a great variety of exogenous and endogenous agents and externally applied electric and magnetic fields are known to be able to produce some hearing sensation [12]. Despite all these considerations and evidence, only recently, some studies have analyzed the effects of mobile phones on the auditory system $[13,14]$. However, the results are not completely consistent.

Only limited research data concerning interaction between EMF emitted by mobile phones and auditory function and possible impact on hearing, are available in the literature. The animal experiments using distortion product otoacoustic emissions (DPOAEs) did not show statistically significant changes on the OHC functionality of adult and developing rats exposed as long as 30 days 1$2 \mathrm{~h}$ per day to EMF at $900 \mathrm{MHz}$ and $1800 \mathrm{MHz}$ frequencies $[15,16]$.

No measurable change in evoked otoacoustic emissions (OAEs) was detected and none of the subjects reported a deterioration in hearing threshold level after 10-min exposure to the EMFs emitted by mobile phones in a recent human study on possible effects of the EMF of mobile telephones on hearing [17]. Other studies based on the auditory brainstem response and middle latency response methods concluded that 30 min mobile phone use has no short-term adverse effects on the human auditory system $[18,19]$. The small amount of publications shows that there is a big gap in the knowledge of potential biological effects of cellular phone use on hearing.

The aim of the present study was to assess the acute potential changes in human hearing function as a consequence of exposure to low-intensity EMF's produced by mobile phones at frequencies of 900 and $1800 \mathrm{MHz}$ and a shamexposure under double-blind conditions as determined by changes in transient evoked otoacoustic emissions (TEOAEs) and hearing threshold levels (HTL) in pure tone audiometry (PTA).

\section{Methods}

The protocol of the study was elaborated in the frame of European Commission $5^{\text {th }}$ Framework project "GUARD: potential adverse effects of GSM cellular phones on hearing".

The study group consisted of 30 healthy volunteers (mean age $23.6 \pm 1.2$ years; range $18-29$ years) without any evidence of hearing or ear disorder. There were 18 males (mean age $22.8 \pm 1.7$ years; range $18-28$ years) and 12 females (mean age $24.9 \pm 1.8$ years; range $18-29$ years).

The participants satisfied the following inclusion criteria: age between 18 and 30 years, no history of otological disorder and/or familial hearing disorder, no self reported hearing difficulty or persistent tinnitus, no exposure to severe noise, no ototoxic drugs, no excess consumption of alcohol or drugs 24 hours prior the testing. Instrumental examination: normal appearance of tympanic membrane on otoscopy, hearing threshold levels (HTL) in both ears no worse that $20 \mathrm{~dB}(\mathrm{~A})$ at any of the standard audiometric frequencies between 0.5 and $8 \mathrm{kHz}$ (Interacoustics AC-40 audiometer, Denmark), no evidence of conductive hearing loss based on air-conduction and bone-conduction audiograms, normal tympanograms and acoustic reflexes present in both ears for stimulation using a $1 \mathrm{kHz}$ tone at $100 \mathrm{~dB}$ HL (Interacoustics AT $235 \mathrm{~h}$ tympanometer, Denmark), presence of clear recordable TEOAE, defined as SNR greater than $6 \mathrm{~dB}$ in two or more half octave bands centred at 1, 2 and $3 \mathrm{kHz}$ (Otodynamics ILO-88 system, London).

All participants attended two study sessions: genuine and sham exposures. The administration of genuine or sham exposure was double blind and counterbalanced in order. Genuine or sham EMF exposures were performed on separate days (at least 24 hours apart) with the tested participant and tester both blind to the condition being used.

The study session consisted of baseline audiological and TEOAE measurements, genuine or sham GSM mobile phone exposure, and followed immediate repeated audiological and TEOAE measurements. Post-exposure measurements were performed in the same order as preexposure for each participant.

Pure tone audiometry (PTA) consisted of air conduction using 2-dB steps in the test ear only. TEOAE measurement was used to record TEOAEs according to "linear" protocol using clicks at $80 \mathrm{~dB}$ SPL. (Analysis time was $20 \mathrm{~ms}, 260$ stimuli). Each TEOAE measurement run included a minimum of 260 "sweeps". A TEOAE was defined as the response if its amplitude was more than $3 \mathrm{~dB}$ above the level of the noise floor. Reproducibility more than $60 \%$ 


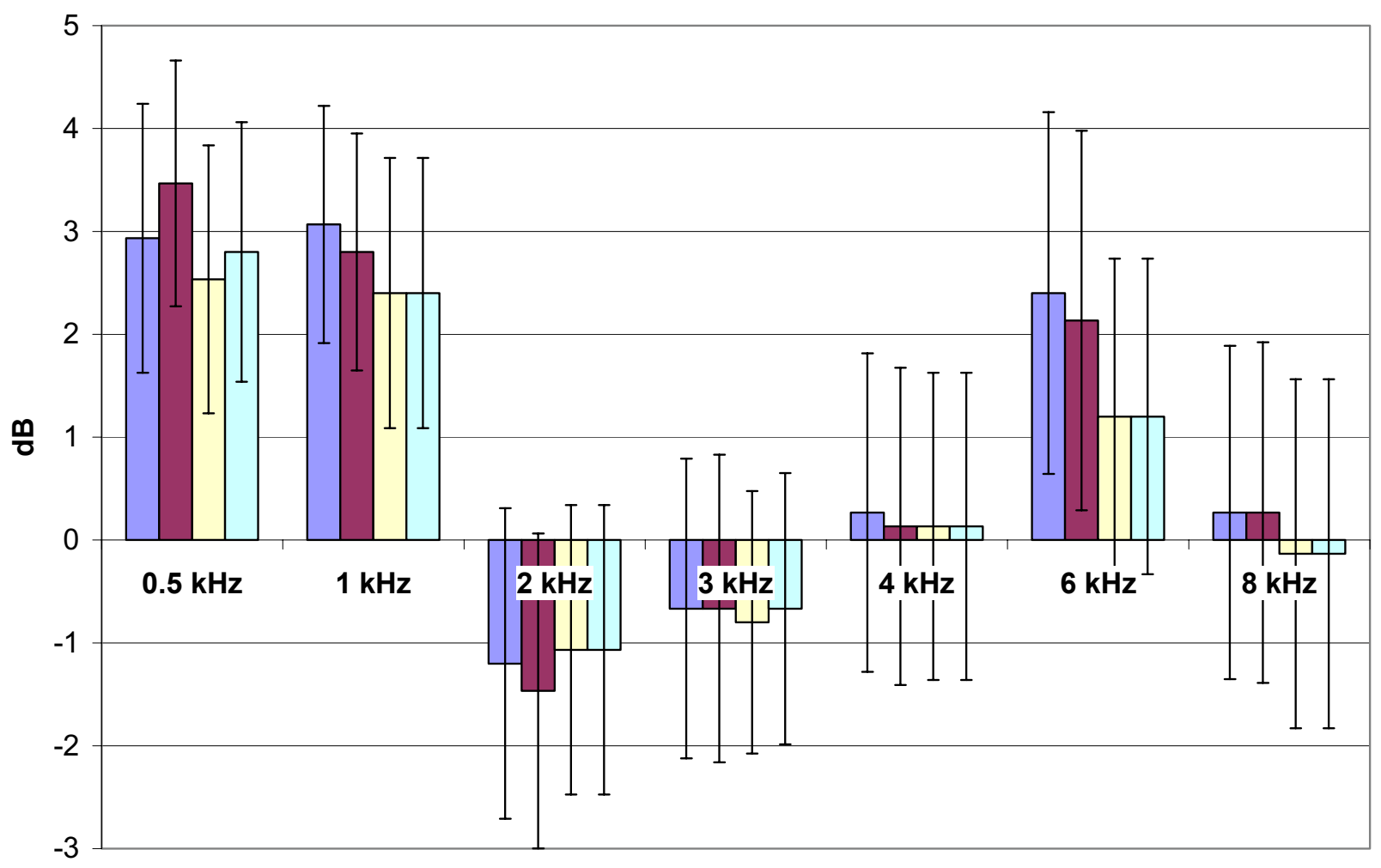

exposure before $\square$ exposure after $\square$ sham before $\square$ sham after

Figure I

Hearing threshold levels ( $900 \mathrm{MHz}$ exposure subgroup). Mean \pm SEM, $\mathrm{p}>0.05$

was considered acceptable for the analysis at 3 successive frequency bands ranging from 1 to $3 \mathrm{kHz}$.

GSM exposure utilized the normal output of a consumer mobile phone (NOKIA 6310) at full power for $10 \mathrm{~min}$ utes. Fifteen participants received GSM exposure at 900 $\mathrm{MHz}$ (full power $2 \mathrm{~W}$ ) and the other fifteen participants received GSM exposure at $1800 \mathrm{MHz}$ (full power $1 \mathrm{~W}$ ). The exposure consisted of speech at a typical conversational level via an insert earphone to one ear, plus GSM exposure in either genuine (test) or sham (control) conditions. All test were performed in a sound-treated $2.5 \times 2.0$ m booth.

The NOKIA 6310 GSM mobile phone without SIM card (checked for correct power output) was used for GSM exposure. Control for carrier frequency, output level, transmit/receive mode of the mobile phone was utilized using specialized PHOENIX software. Therefore the mobile phone was connected via serial data cable from the PC to the phone.
To simulate the normal use of a mobile phone the participants were simultaneously exposed to both GSM radiation and an acoustic stimulus (speech material $10 \mathrm{~min}$ of duration). However, to prevent any possible effects from using the speaker in the handset, the speech material was delivered via an insert phone (EAR tone 3A ABR). The insert phone was used without the ear tip inserted and, therefore, the tube was taped along the subject's jaw with the entrance of the tube placed at the tragal notch of the ear. The standard speech material duration of 10 minutes, read out by male speaker, was digitally recorded on minidisk (Sony MiniDisc Recorder MDS 101). Then the speech sample was filtered (Syntrilium "Cool Edit") amplifying the low frequencies of the speech to compensate to some extent for the frequency weighting of the tragal presentation, so that the speech did not sound too unnatural. Having re-recorded the filtered material, the speech sample was calibrated in 2-cc couples (Bruel \& Kjer type 4152, Denmark) to the required level in order to produce a sound pressure level at the ear drum equivalent to free field speech level of approximately $60 \mathrm{~dB}(\mathrm{~A})$. A sound 


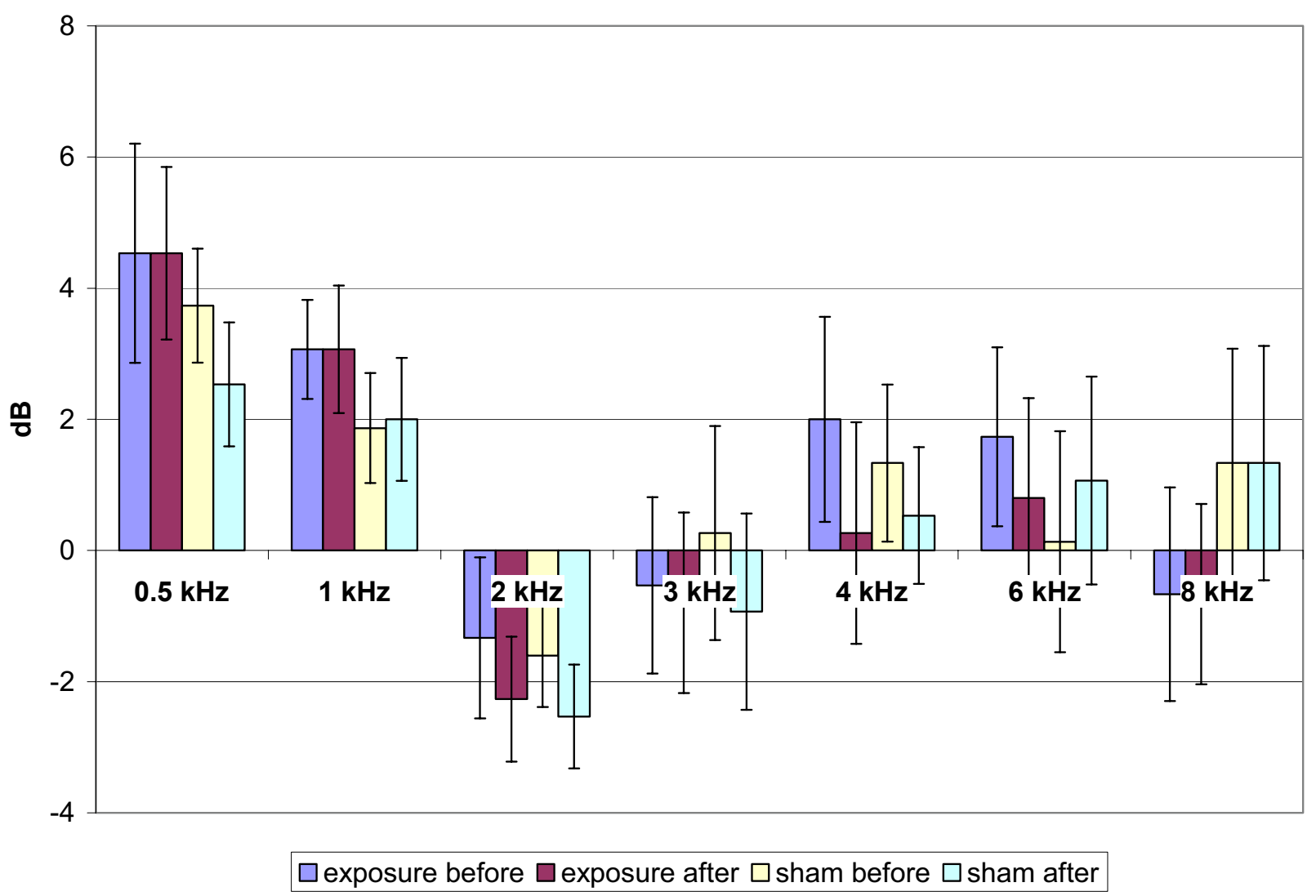

Figure 2

Hearing threshold levels (I800 MHz exposure subgroup). Mean \pm SEM, $\mathrm{p}>0.05$

replay system used to replay speech to the ear of the participant consisted of minidisk player, audiometer and insert earphone.

During the test session NOKIA 6310 mobile phone was fixed to the tested ear using special headband and positioning system, so that the centre of the radiated field should be over the entrance of the external ear canal. All parts of the positioning system were made by non-metallic plastic materials in order to avoid any perturbation of the EMF emitted by the mobile phone. The subjects tested were asked to perform an attention task so that they attend to the speech stimulus, such as counting the number of a specific word in the speech material. After the completion of the GSM exposure the participants were asked appropriate questions about the speech material and their experience of any possible subjective effect from the exposure.

The study has been acknowledged by An Independent Ethics Committee of Kaunas University of Medicine and is in compliance with the Helsinki Declaration.

\section{Statistics}

A statistical analysis was performed with the SPSS 12.0 (Statistical Package for Social Sciences) for Windows. Means of the groups and standard errors of the means (SEM) for each parameter were obtained for the genuine and sham GSM exposure. Confidence interval (CI) of 0.95 was chosen for statistical evaluation and significance level of 0.05 was chosen for testing statistical hypotheses. As all the participants underwent four-times testing (pre/post genuine exposure and pre/post sham exposure), four dependent samples of repeated measures were obtained. Therefore, for the comparison of the means of the audiological parameters in the total group $(n=30)$ Repeated Measures Analysis of Variance was used. An Exact Friedman Test was used for the comparison of the means of the audiological parameters in the groups tested for $900 \mathrm{MHz}$ and $1800 \mathrm{MHz}$ EMF frequncies ( $\mathrm{n}=15$ each), respectively.

\section{Results}

The subjects tested in the study tolerated the EMF exposure of mobile phones quite well. There were no subjective complaints after the exposure. 


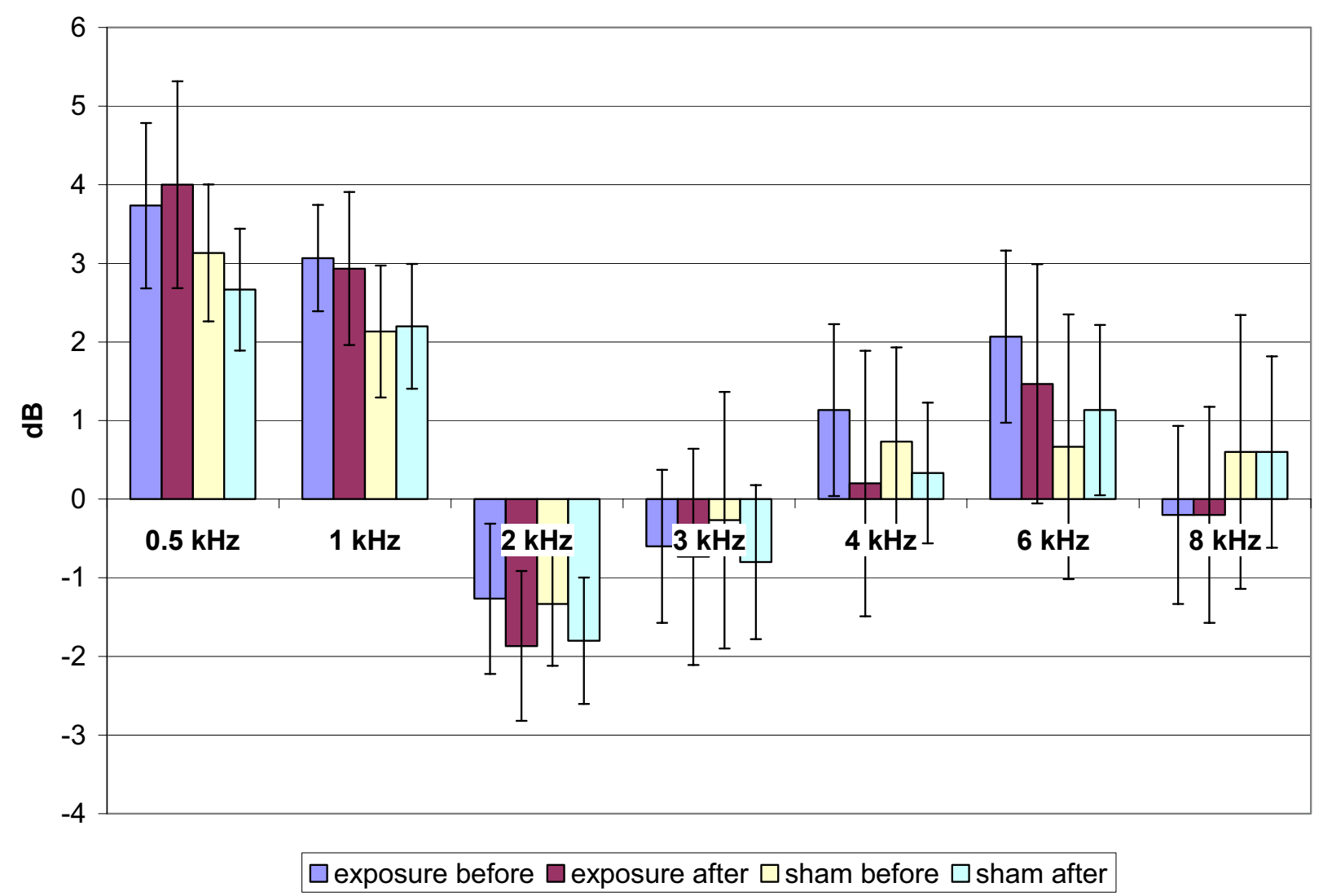

Figure 3

Hearing threshold levels (total group, $n=30$ ). Mean \pm SEM, $p>0.05$

The means of air conduction HTL of PTA throughout the testing frequencies of pre/post genuine and pre/post sham GSM exposure are presented in Fig. 1 for $900 \mathrm{MHz}$ exposure, in Fig. 2 for $1800 \mathrm{MHz}$ exposure and in Fig. 3 for the total group, respectively. The analysis of means of HTL of the PTA with the Repeated Measures Analysis of Variance and Exact Friedman Test did not reveal any statistically significant differences between pre/post genuine and pre/ post sham exposure groups ( $\mathrm{p}>0.05)$.

As all of the subjects tested in the study had a normal hearing, recordings of TEOAEs were obtained (6-10 dB) above the noise floor through $1-3 \mathrm{kHz}$ test frequency range for all sessions. Reproducibility of TEOAEs was $>60 \%(91 \pm 3$ $\%$ in average). The mean amplitude shifts of the TEOAE measurements of pre/post genuine and pre/post sham GSM exposure are presented in Fig. 4 for $900 \mathrm{MHz}$ exposure, in Fig. 5 for $1800 \mathrm{MHz}$ exposure and in Fig. 6 for the total group, respectively. Statistical analysis with the Repeated Measures Analysis of Variance and Exact Friedman Test did not reveal any statistically significant differences in mean TEOAEs amplitude shifts between genuine and sham exposure groups ( $\mathrm{p}>0.05)$. The data collected showed that average TEOAE levels (averaged across a frequency range) changed less than $2.5 \mathrm{~dB}$ between pre- and post-, genuine and sham exposure. The greatest individual change was $10 \mathrm{~dB}$, with a decrease in level from pre- to post- real exposure.

The results of the present study suggest that 10-min exposure to EMFs emitted by GSM mobile phone did not cause any detectable alterations in neither PTA nor TEOAEs.

\section{Discussion}

GSM mobile phones have become very commonly used throughout the world within a short period of time. This 


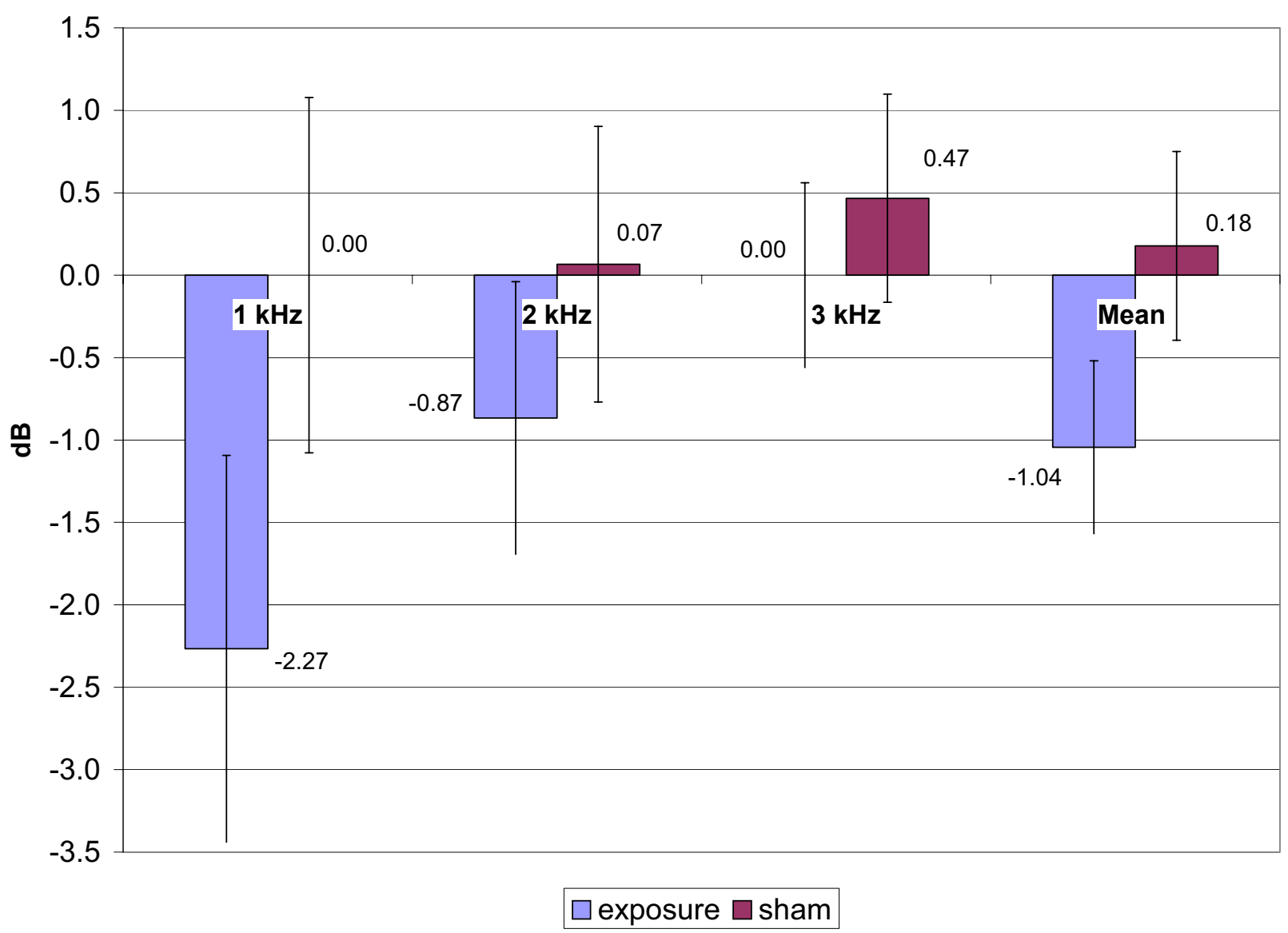

Figure 4

TEOAE amplitude shifts ( $900 \mathrm{MHz}$ exposure subgroup). Mean \pm SEM, $p>0.05$

has given rise to concern about potential influences of EMF emitted by mobile phones on health. Although there is no clear evidence to demonstrate harmful physiological effects of EMF at the levels used by mobile phones, however, there is a widespread public concern that there may be some potential harm [8-11,20-22].

Potential effects of mobile phone EMF radiation on hearing should be considered as one of the major priorities in the research of potential adverse effects of mobile phone use. Mobile phones are usually held in the closest proximity to the external ear and therefore, EMF exposure at the ear is high due to radiation from a remote earpiece. Since the cochlea is enclosed by very dense compact bone, located relatively deep, congested with the perilymph and endolymph, they all help to shield it from the mobile phone EMF [17]. However, the OHC of the inner ear are known to be the most sensitive and vulnerable elements of the auditory pathway. If subtle cochlear involvements occur, they might be detected through changes in TEOAEs, which directly reflect the function of cochlear OHC. Even minor changes in the functioning of OHCs, caused by various noxious factors, are known to considerably affect TEOAE amplitude [23-26]. On the other hand, TEOAEs represent acoustic responses of OHCs, which act like mechanoreceptor cells that generate force in their cell bodies to amplify sound and provide the exquisite sensitivity of the cochlea $[27,29]$. Consequently, the piezoelectric properties of OHCs that are essential for hearing might be relatively easily damaged by external EMFs emitted by mobile phones. Therefore, the present study in addition to conventional measures of HTL, which require a subjective response, employed an objective methodology of registration of TEOAE that is able to detect very small effects in hearing function with appropriate statistical power. 


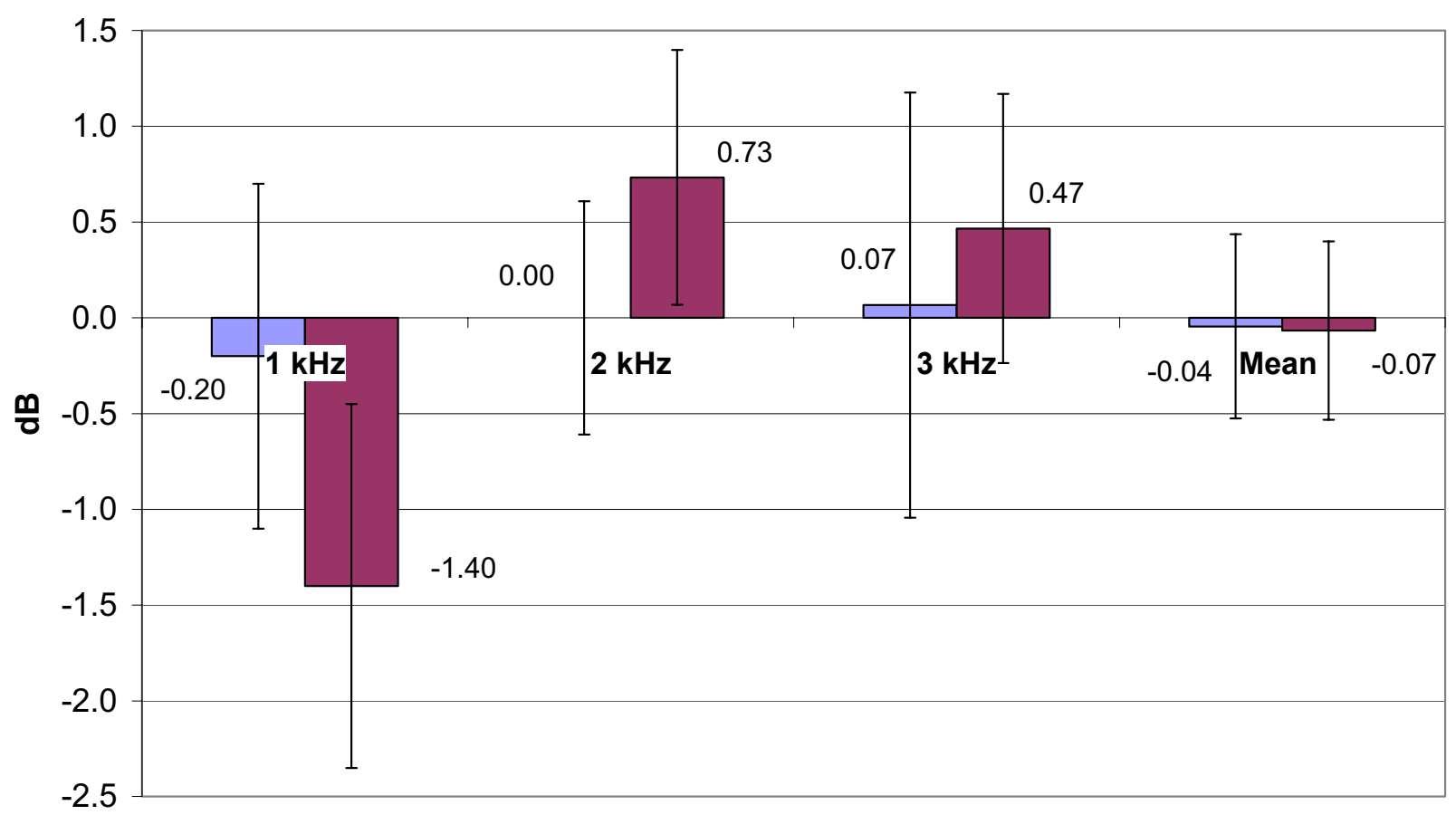

$\square$ exposure $\square$ sham

Figure 5

Mean TEOAE amplitude shifts (I $800 \mathrm{MHz}$ exposure subgroup, $\mathrm{n}=15)$. Mean $\pm \mathrm{SEM}, \mathrm{p}>0.05$

The experimental paradigm used in this study was the within-subject paradigm. This paradigm provided audiological measurements immediately before and immediately after exposure to EMF via a commercial mobile phone. As the procedure was conducted twice: one with a genuine exposure and one with a sham exposure, this approach maximized sensitivity to change, because between subjects' variations in the results were minimised by calculation of the difference between before and after measurements. A double-blind design of the procedure maximized objectivity of the experiment. EMF exposure dose used in the study was necessarily low but comparable with the use of the mobile phones in normal day life.

As stated above, statistical analysis of the results of the present study did not reveal any significant alterations of HTL after 10 min GSM mobile phone exposure. However, the main focus of this study was to analyse the effects of EMF of mobile phones on the TEOAE recorded before and immediately after a sham and a genuine exposure in a group of young subjects. The data collected showed that average TEOAE levels (averaged across a frequency range) changed less than $2.5 \mathrm{~dB}$ between pre- and post-, genuine and sham exposure. Therefore the variability of the TEOAE recorded before and after the GSM exposure and the individual variability appeared to be small and not statistically significant. This allows us to state that $10 \mathrm{~min}$ of EMF exposure at the maximum power (peak power: 1 $\mathrm{W}$ or $2 \mathrm{~W}$ according to the frequency) does not induce any measurable changes in the TEOAEs.

Some other unanswered questions of the present study should be mentioned. The measurements used in the study have been restricted by the frequency spectrum of the commercially available TEOAE equipment. Possibly, higher frequency instruments could be able to reveal more comprehensive information about the effects of EMF exposure [17]. As the study protocol was based on the comparison of the measures of the audiological tests obtained before and immediately after EMF exposure, only a relatively long-term or chronic alteration in hearing function could be detected by the present investigations. Some potential transitory, i.e. reversible, alterations in hearing function lasting for only a short time during the EMF exposure cannot be detected by these methods. Therefore, the simultaneous measurement of hearing 


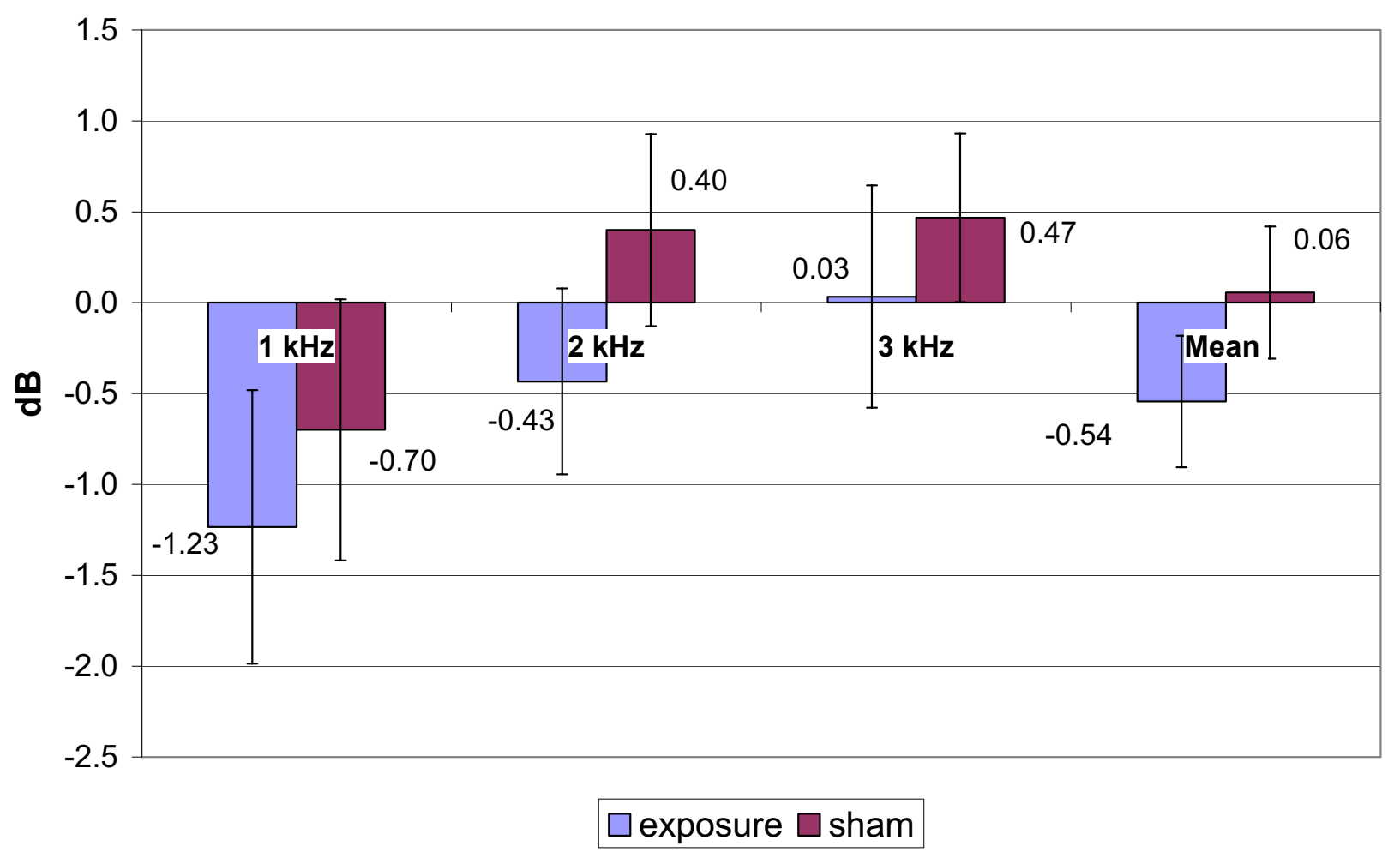

Figure 6

Mean TEOAE amplitude shifts (total group, $n=30$,) Mean \pm SEM, $p>0.05$

function during the mobile phone's EMF emission would be of scientific interest. However, these implications could be considered as guidelines for further investigations.

\section{Conclusion}

It could be concluded that a 10-min close exposure of EMFs emitted from a mobile phone had no immediate after-effect on measurements of HTL of PTA and TEOAEs in young adult human subjects and no measurable hearing deterioration at least at outer and middle ear and cochlear levels was detected in our study.

\section{Competing interests}

The author(s) declare that they have no competing interests.

\section{Authors' contributions}

IU has been the principal investigator, participated in study design and coordination and helped to draft the manuscript. VU participated in the planning of the study and coordinated the writing of the manuscript. VS performed the statistical analysis. EG participated in acquisi- tion of audiological data. All authors contributed to the interpretation of results, have read and approved the final manuscript.

\section{Acknowledgements}

This study was sponsored by European Commission 5FW project "GUARD: potential adverse effects of GSM cellular phones on hearing".

Contract number: QLK4-CT-00I50

\section{References}

I. Oftedal G, Wilen J, Sandstrom M, Mild KH: Symptoms experienced in connection with mobile phone use. Occup Med (Lond) 2000, 50:237-245.

2. Frey $\mathrm{AH}$ : Headaches from cellular telephones: are they real and what are the implications? Environ Health Perspect 1998, 106: I0I-I03.

3. Borbely AA, Huber R, Graf T, Fuchs B, Gallmann E, Achermann P: Pulled high-frequency electromagnetic field affects human sleep and sleep electroencephalogram. Neurosci Lett 1999, 275:207-210.

4. Preece AW, Iwi G, Davies-Smith A: Effect of a 9/5-MHz simulated mobile phone signal on cognitive function in man. Int J Radiat Biol 1999, 75:447-456.

5. Hamblin DL, Wood AW, Croft RJ, Stough C: Examining the effects of electromagnetic fields emitted by GSM mobile phones on human event-related potentials and performance during an auditory task. Clin Neurophysiol 2004, I I 5: I7I- I 78.

6. Fritze K, Sommer C, Schmitz B: Effect of global system for mobile communication (GSM) microwave exposure on 
blood-brain barrier permeability in rat. Acta Neuropathol (Berl) 1997, 94:465-470.

7. Haarala C, Aalto S, Hautzel H, Julkunen L, Rinne JO, Laine M, Krause B, Hamalainen H: Effects of a $902 \mathrm{MHz}$ mobile phone on cerebral blood flow in humans: a PET study. Neuroreport 2003, 14:2019-2023.

8. Moulder JE, Erdreich LS, Malyapa RS, Merritt J, Pickard WF, Vijayalaxmi : Cell phones and cancer: what is the evidence for a connection? Radiat Res 1999, I 5 I:5 | 3-53 I.

9. Blettner M, Berg G: Are mobile phones harmful? Acta Oncol 2000, 39:927-930.

10. Christensen HC, Schuz J, Kosteljanetz M, Poulsen SH, Thomsen J, Johansen Christoffer J: Cellular telephone use and risk of acoustic neuroma. Am J Epidemiol 2004, I 59:277-283.

II. Lonn S, Ahlbom A, Hall P, Feychting M: Mobile phone use and the risk of acoustic neuroma. Epidemiology 2004, 1 5:653-659.

12. Watanabe Y, Tanaka T, Taki M, Watanabe S: FDTD Analysis of Microwave Hearing Effect. IEEE Trans Microwave Theory Tech 2000, 48:2I $26-2132$.

13. Kellenyi L, Thurockzy G, Faludy B, Lenard L: Effects of mobile GSM radiotelephone exposure on the auditory brainstem response (ABR). Neurobiology 1999, 7:79-8I.

14. Marino C, Cristalli G, Galloni P, Pasqualetti P, Piscitelli M, Lovisolo GA: Effects of Micro-waves $(900 \mathrm{MHz})$ on the cochlear receptor: exposure systems and preliminary results. Radiat Environment Bioph 2000, 39:13|-136.

15. Parazzini M, Marino C, Galloni P, Piscitelli M, Tognola G, Grandori F, Ravazzani P: Effects of electromagnetic fields on hearing: study of the influence of GSM cellular phones on the inner auditory system of Sprague-Dawley rats. Proceedings 2 nd Medical and Biological Engineering Conference, Vienna :I290-I. 2002, December 4-8

16. Kizilay A, Ozturan O, Erdem T, Kalcioglu T, Miman MC: Effects of chronic exposure of electromagnetic fields from mobile phones on hearing in rats. Auris Nasus Larynx 2003, 30:239-245.

17. Ozturan O, Erdem T, Miman MC, Kalcioglu MT, Oncel S: Effects of the electromagnetic field of mobile telephones on hearing. Acta Otolaryngol 2002, I 22:289-293.

18. Arai N, Enomoto H, Okabe S, Yuasa K, Kamimura Y, Ugawa Y: Thirty minutes mobile phone use has no short-term adverse effects on central auditory pathways. Clin Neurophysiol 2003, I 14:1390-1394.

19. Bak M, Sliwinska-Kowalska M, Zmyslony M, Dudarewicz A: No effect of acute exposure to the electromagnetic field emitted by mobile phones on brainstem auditory potentials in young volunteers. Int J Occup Med Environ Health 2003, 16:201-209.

20. Weinberger Z, Richter ED: Cellular telephones and effects on the brain: the head as an antenna and brain tissue as a radio receiver. Med Hypotheses 2002, 59:703-705.

21. Kompis M, Hausler R: Electromagnetic interference of boneanchored hearing aids by cellular phones revisited. Acto Otolaryngol 2002, | 22:5 I0-5 |2.

22. Samkange-Zeeb F, Berg G, Blettner M: Validation of self reported cellular phone use. J Expo Anal Environ Epidemiol 2004, 1 4:245-248.

23. Skellett RA, Crist JR, Fallon M, Bobbin RB: Chronic low-level noise exposure alters distortion product otoacoustic emissions. Hearing Res 1996, 98:68-76.

24. Janssen $T$, Boege $P$, Oestreicher $E$, Arnold $W$ : Tinnitus and $\mathbf{2} \mathbf{f}_{1}-\mathbf{f}_{2}$ distortion product otoacoustic emissions following salicylate overdose. J Acoust Soc Am 2000, I 07: 1790- 1792.

25. Frank AM, Alexiou C, Hulin P, Janssen T, Arnold W, Trappe AE: Non-invasive measurement of intracranial pressure changes by otoacoustic emissions (OAEs) - a report of preliminary data. Zentralbl Neurochir 2000, 61 : 177-180.

26. Ravazzani P, Tognola G, Parazzini M, Grandori F: Principal component analysis as a method to facilitate fast detection of transient-evoked otoacoustic emissions. IEEE Trans Biomed Eng 2003, 50:249-252.

27. Parazzini M: Radiofrequency electromagnetic fields produced by mobile phones on the auditory system: study on biological effects and numerical dosimetry. Doctoral thesis, Istituto di Ingegneria Biomedica CNR, Milan 2004.

28. Dallos P: The active cochlea. Neurosci 1992, I 2:4575-4585.

29. Zheng J, Shen W, He DZ, Long KB, Madison LD, Dallos P: Prestin is the motor protein of cochlear outer hair cells. Nature 2000 , 405: $149-155$.

\section{Pre-publication history}

The pre-publication history for this paper can be accessed here:

http://www.biomedcentral.com/1471-2458/5/39/prepub
Publish with Biomed Central and every scientist can read your work free of charge

"BioMed Central will be the most significant development for disseminating the results of biomedical research in our lifetime. "

Sir Paul Nurse, Cancer Research UK

Your research papers will be:

- available free of charge to the entire biomedical community

- peer reviewed and published immediately upon acceptance

- cited in PubMed and archived on PubMed Central

- yours - you keep the copyright
Biomedcentral 